\title{
Magnetooptical and Magnetoresistive Properties of Solid-Solution Films
}

\author{
Cheshko I.V., Kondrakhova D.M., Odnodvorets L.V., Pylypenko O.O., Shabelnyk Yu.M. \\ Department of Applied Physic, Faculty of Electronics and Informational Technologies, Sumy State University, Sumy, 2, \\ Rymskyi-Korsakov Str. 40007, Ukraine \\ *Corresponding Author: larysa.odnodvorets@gmail.com
}

Copyright @ 2013 Horizon Research Publishing All rights reserved.

\begin{abstract}
The results of study magnetooptical and magnetoresistive properties of multilayers based on $\mathrm{Co}, \mathrm{Fe}$ and $\mathrm{Cu}, \mathrm{Ag}$ or $\mathrm{Au}$, in which are formed solid solutions (s.s.) with possible subsequent formation the granular state are presents. The dimensional and concentration dependences of the magnetooptical Kerr effect and magnetoresistance for two-layer systems and multilayers with different types of solubility (for systems based on $\mathrm{Cu}$ and $\mathrm{Co}$ is unlimited, as for $\mathrm{Co}$ and $\mathrm{Au}, \mathrm{Ag}$ and $\mathrm{Co}$ - limited) at different stages of annealing was received and analyzed. Established the basic regularities of influence by processes of formation s.s. $(\mathrm{Cu}$, $\mathrm{Co}),(\mathrm{Au}, \mathrm{Co})$ and $(\mathrm{Ag}, \mathrm{Co})$ in the film systems obtained layering condensation with followed annealing on the magnetic properties on the whole film system. It is shown that in systems where similar processes of formation s.s. are absent (the system based on $\mathrm{Fe}$ and $\mathrm{Ag}$ ) magnetic properties depend only on the concentration of magnetic components and common thickness of the sample.
\end{abstract}

Keywords Thin Film, Magnetoresistance, Magnetic Anisotropy, Solid Solution, Magnetooptical Kerr Effect

\section{Introduction}

Materials with the spin-dependent scattering of electrons as multilayers or granular alloys based on magnetic ( $\mathrm{Co}$ or $\mathrm{Fe}$ ) and nonmagnetic $(\mathrm{Cu}, \mathrm{Au}$ or $\mathrm{Ag})$ layers widely used for the formation of modern functional electronic elements [1-2]. However, several authors [3-6] after structural characteristics study of such system formation of disordered the replacement solid solutions (s.s.) based on fcc - lattices of $\mathrm{Cu}, \mathrm{Ag}$ and $\mathrm{Au}$ during condensation or annealing is observed. In some cases granulation of magnetic components are take place. Such processes of phase formation are breaking integrity of the individual layers and interfaces, which play a important role in the spin-dependent electron scattering. As a result of complex multilayer film systems take fundamentally new form with other electrophysical and galvanic-magnetic properties.
In work [3] based on results study of structure-phase state of film systems based on $\mathrm{Co}$ and $\mathrm{Cu}$ obtained by simultaneous condensation study the complete cycle of s.s. $(\mathrm{Cu}, \mathrm{Co})$ formation, its decomposition and fool of $\mathrm{Co}$ granules. The authors conclude the formation of the fcc phase of solid solution, which enriched $\mathrm{Cu}$ atoms and other one enriched in Co atoms in accordance with the increase and decrease of lattice parameter during condensation. Next in the process of vacuum annealing occurred partial decay of s.s., and then at the temperature $1000 \mathrm{~K}$ the authors observed the full Co selection with the formation of granular state. In work [4] are indicate similar processes of formation of s.s. $(\mathrm{Cu}, \mathrm{Co})$ based on $\mathrm{fcc} \mathrm{Cu}$ lattice but in the multilayer film systems in the layering condensation at the whole the range of the common concentration of Co atoms, which authors [7] explained to very close values of the lattice parameters of the system components. But the conclusions of $[5,6]$ show that systems based on $\mathrm{Co}$ and $\mathrm{Ag}$ or $\mathrm{Au}$ with great difference of lattice parameters can form s.s. and they demonstrate a higher tendency to form granular alloy during annealing. For example, in work [5] reported about formation of ferromagnetic $\mathrm{Co}$ granules in the matrix of s.s. ( $\mathrm{Au}, \mathrm{Co}$ ), which formed by annealing the two-component films up to temperatures from 500 to $700 \mathrm{~K}$. Even for systems based on $\mathrm{Ag}$ and Co which have a limited solubility (less than $3 \%$ in a bulk state [8]) in work [6] was reported of possible formation of s.s. with a maximum displacement of lattice parameters at 60 at. $\% \mathrm{Co}$ on the temperature range $600-700 \mathrm{~K}$.

In works $[9,10]$ have been attempts to analyze the impact of structural-phase state at the magnetorestive properties in the multilayers based on two-layer fragments $\mathrm{Fe} / \mathrm{Cr}, \mathrm{Fe} / \mathrm{Cu}$ and $\mathrm{Co} / \mathrm{Cu}$. For the mostly in the film systems with possible realization of spin-dependent electron scattering the issue of dependence of the magnetic properties of different factors (degree of solubility of the component, annealing, the thickness of the separate layers, etc.) poorly understood.

The aim of this study was to establish the influence of formation solid solutions in film systems based on $\mathrm{Co}, \mathrm{Fe}$ and $\mathrm{Cu}, \mathrm{Ag}$ or $\mathrm{Au}$ on their magnetic and magnetoresistive properties. 


\section{Technique and Experimental Results}

\subsection{Experimental Technique}

The influence of the conditions of annealing and total concentration of magnetic component on the magnetoresistive and magnetooptical properties of multilayer film systems based on $\mathrm{Co}$ or $\mathrm{Fe}$ (with intermediate layers of $\mathrm{Cu}, \mathrm{Au}$ and $\mathrm{Ag}$ ) with the possible stabilization of s.s. of replacement based on fcc - lattice of $\mathrm{Cu}, \mathrm{Au}$ and $\mathrm{Ag}$ were analyzed. Two- and multilayer film systems based on Co and $\mathrm{Au}, \mathrm{Co}$ and $\mathrm{Cu}$ and $\mathrm{Co}$ and $\mathrm{Ag}$ were obtained layering condensation component of electron beam method $(\mathrm{Co})$ and by the thermal evaporation $(\mathrm{Fe}, \mathrm{Cu}, \mathrm{Au}$ and $\mathrm{Ag})$ with temperature of substrate $T_{a}=300 \mathrm{~K}$ (at the formation of three-layer $\mathrm{Co} / \mathrm{Cu} / \mathrm{Co} / \mathrm{S}(\mathrm{S}$ - substrate) temperature of substrate was $460 \mathrm{~K}$ ). The condensation was carried out on a substrate of amorphous ceramics (for studies of magnetoresistive and magnetooptical properties) and carbon film (for electron-diffraction studies). The thickness of the individual layers of the film system controlled by two methods: by quartz resonator (during condensation) and by optical interferometer (after condensation).

To the compare the effects on the magnetooptical and magnetoresistive properties of the processes s.s. formation were studied film systems based on $\mathrm{Fe}$ and $\mathrm{Ag}$, obtained by simultaneous condensation, in which formed a mechanical mixture without formation s.s.

Heat treatment of samples was carried in high vacuum at temperatures $T_{a}=300-1000 \mathrm{~K}$ by scheme «the heating $\rightarrow$ shutter speed for $15 \mathrm{~min} \rightarrow$ cooling to room temperature». The control the rate of heating and cooling, exposure time, temperature of substrates was performed in automatic mode using the hardware and software based on 16-bit sigma-delta ADC ADAM-4118 using the technique proposed in [11].

The study of magnetoresistive properties was conducted at room temperature using four-point compensation schemes in the external magnetic field with strength $B= \pm$ $450 \mathrm{mT}$. The current flowed in the plane of the sample, and measurements of magnetoresistance were carried out at three measurement geometries: longitudinal, transverse and perpendicular. The value of magnetoresistance is determined by the ratio

$$
M R=\frac{\Delta R}{R_{0}}=\frac{\left(R_{B}-R_{B_{\max }}\right)}{R_{B_{\max }}},
$$

where $R_{B}$ and $R_{B_{\max }}$ - resistance of film in field and resistance of film at the maximum field. In the studied systems except MR and giant magnetoresistance (GMR) are also observed anisotropic magnetoresistance (AMR). Magnetooptical properties of the film samples were investigated using magnetooptical Kerr effect, which is to change the polarization of light reflected from the sample surface, when you make it to the magnetic field. The crystal structure and phase composition of the samples was investigated by electron microscopy and electron diffraction.

\subsection{Structure and Phase State of Systems Based on Co, $\mathrm{Cu}, \mathrm{Au}$ and $\mathrm{Ag}$}

According to state diagrams for bulk samples [8] the system of Au-Co and $\mathrm{Ag}-\mathrm{Cu}$, as opposed to system based on $\mathrm{Cu}-\mathrm{Co}$ and $\mathrm{Fe}-\mathrm{Au}$ have limited solubility. Unlike bulk samples, the film samples are exposed to mutual solubility and to the formation of granular alloy at certain conditions. The study of structural and phase state of multilayer systems based on $\mathrm{Co}$ and $\mathrm{Au}$ or $\mathrm{Ag}$ indicated on identity layer in not annealed state over the entire range of thicknesses $(d=1-50$ nm) (Figure 1).

Annealing to temperature $T_{a} \geq 700 \mathrm{~K}$ is observed the characteristic decrease of the parameter fcc lattice $\mathrm{Au}$ or $\mathrm{Ag}$ and $\left(d_{C o}>8 \mathrm{~nm}\right)$ fading lines of pure Co (Figure 1B). This can be explained by the formation in this system disordered s.s. replacement $(\mathrm{Au}, \mathrm{Co})$ or $(\mathrm{Ag}, \mathrm{Co})$ respectively, due to thermally diffusion processes. With relatively large thickness of the initial layer (more than $10 \mathrm{~nm}$ ) along the lines of s.s. one can see lines from the layer of pure $\mathrm{Au}$ or $\mathrm{Ag}$. With further annealing to a temperature of $T_{a}=850 \mathrm{~K}$ and above, with lines which corresponding to the hep-Co and fcc s.s. ( $\mathrm{Au}, \mathrm{Co})$ or $(\mathrm{Ag}, \mathrm{Co})$, as fixed lines from fcc $\mathrm{Co}$, since at a temperature $T_{a}=690 \mathrm{~K}$ is a polymorphic hcp $\rightarrow \mathrm{fcc}$ transition that at small thicknesses can occur at $T_{a} \geq 600 \mathrm{~K}$ [12] .
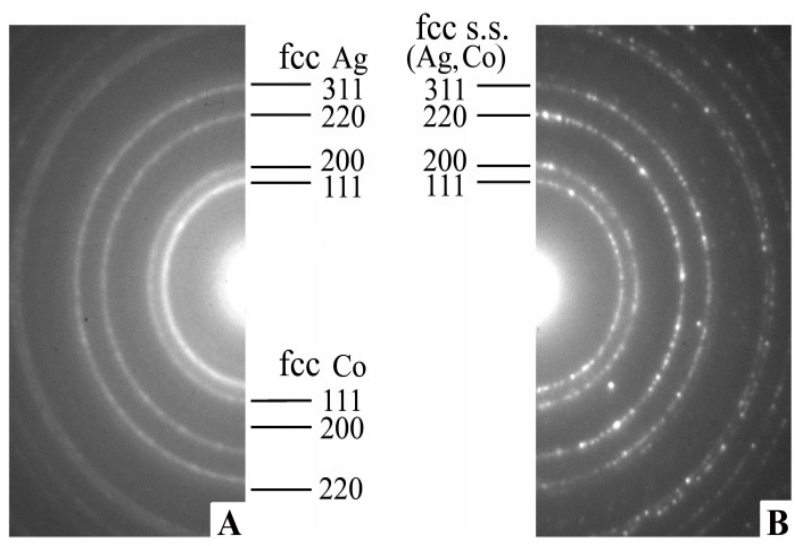

Figure 1. Electron diffraction of multilayer film

$\mathrm{Ag}(10) / \mathrm{Co}(5) / \mathrm{Ag}(10) / \mathrm{Co}(20) / \mathrm{S}$ after condensation (A) and after annealing to $T a=700 \mathrm{~K}$ (B). In parentheses indicate the thickness in $\mathrm{nm}$

Peculiarity the system based on $\mathrm{Co}$ and $\mathrm{Ag}$ can be considered the fact that after heat treatment to $T_{a}=700 \mathrm{~K}$ is observed formation the nanogranule of $\mathrm{Co}$ (the average grain size $6-10 \mathrm{~nm})$ in the matrix of s.s. $(\mathrm{Ag}, \mathrm{Co})$. The similar changes of the phase state are observed on the electron of systems based on $\mathrm{Co}$ and $\mathrm{Cu}$, but with one exception. According to our data and the data of [11] the formation of s.s. $(\mathrm{Cu}, \mathrm{Co})$ based on the fcc $\mathrm{Cu}$ lattice take place in the process of condensation in the whole range of total concentration of atoms Co (Figure 2). 


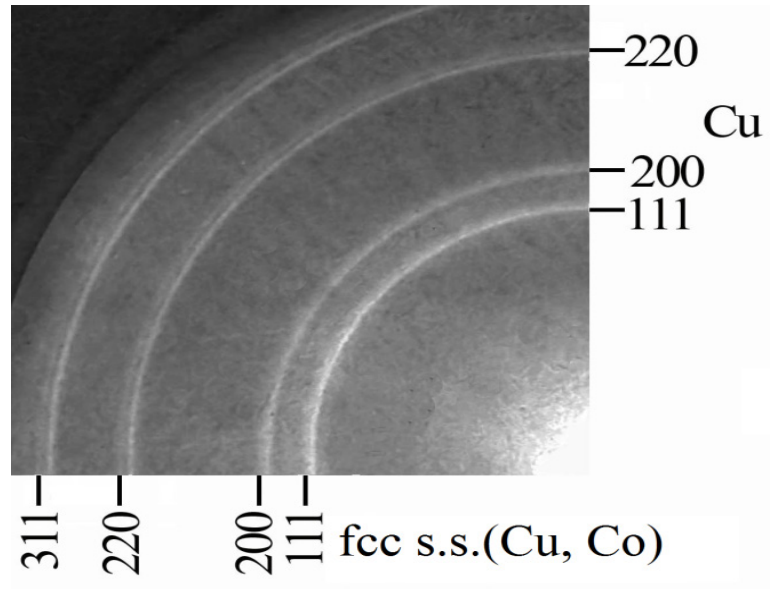

Figure 2. Electron diffraction of $\mathrm{Cu}(10) / \mathrm{Co}(5) / \mathrm{Cu}(10) / \mathrm{Co}(20) / \mathrm{S}$ after condensation

\subsection{MOKE and MR of Film Systems Based on $\mathrm{Co}, \mathrm{Cu}$, Au and Ag}

The experimental data are showing the anisotropy of magnetic properties in polycrystalline ferromagnetic Co films. The detailed MOKE investigations of Co single-layer films with changing the angle of rotation of the sample in the plane of the film relative versus lines of magnetic induction are showing that AMR dependence versus structure and thickness sample and annealing temperature [13]. The maximum anisotropy observed at $T_{a}=(400 \div 600 \mathrm{~K})$. It's can be explained by changes in crystal structure features Co films. Process of healing defects in Co films beginning at relatively low temperatures. This leads to improved domain structure of the film and reflected in the increase AMR of the sample. Significant changes in the structure can be observed at temperatures $600-700 \mathrm{~K}$. In that moment process of the polymorphic transition hcp Co $\rightarrow$ fcc Co is done. In the structure Co film increase the average grain size and coercivity and loss AMR [14].

In multilayer film systems based on Co the value of MOKE depends on anisotropy of magnetic and magnetooptic properties of the solid solution intermediate layer, film alloys and granular alloys. Using as an intermediate layer $\mathrm{Au}$ film in systems based on $\mathrm{Co}$ and $\mathrm{Au}$ leads to a sharp increase coercivity in comparison with single-layer Co films. Annealing of the samples to 700-900 $\mathrm{K}$ resulted to increase grain size and coercivity. For film systems $\mathrm{Au}(35) / \mathrm{Co}(10) / \mathrm{S}$ not annealed the coercivity loop has rectangular form and after $700 \mathrm{~K}$ loses his shape, but not disappear completely. It's can be explained in part diffusion atoms $\mathrm{Co}$ in $\mathrm{Au}$ which loses ferromagnetic structure and including s.s. ( $\mathrm{Au}, \mathrm{Co})$ throughout the bulk of the film structure. Such a form of hysteresis loops can be explaining of the thickness magnetic Co layer. The research MOKE for this system confirming s.s. (Ag, Co) and formation individuals granules Co at $T_{a}=700 \mathrm{~K}$.

Fig. 3 is showing the MOKE dependence of the coercive vs angle measurement for films based on $\mathrm{Co}$ and $\mathrm{Au}$. All three systems had almost identical concentration atoms Co
$\left(c_{C o}=80-90\right.$ aт. \%) and different thickness of the magnetic and nonmagnetic layers (the total thickness of the film $-d=$ $18-68 \mathrm{~nm})$. The coercivity changing from 8 to $14 \mathrm{mT}(d=$ $46-68 \mathrm{~nm})$ and from 5 to $40 \mathrm{mT}$ in $\mathrm{Co}(6) / \mathrm{Au}(5) / \mathrm{Co}(7) / \mathrm{S} \mathrm{film}$ system $(d=18 \mathrm{~nm})$ and depends on temperature of annealing. The maximal values of coercivity observed in annealed samples for $T_{a}=700-900 \mathrm{~K}$. It's can be explained formation s.s. (Co, $\mathrm{Au})[15]$ and granules $\mathrm{Co}$ with average size of 5-1 $\mathrm{nm}$. The maximal anisotropy observed in non-annealing film system with $d=18 \mathrm{~nm}$. The increasing temperature of annealing leads to improved domain structure of the film and increase the value of coercivity.

The systems with a relatively large thickness are almost isotropic which explained formation ordered domain structure. In three-layer $\mathrm{Co} / \mathrm{Cu} / \mathrm{Co} / \mathrm{S}$ system the process including formation s.s. is at the stage of condensation component. It's showing non-precise shape of the curve of MOKE at $300 \mathrm{~K}$ (Figure 4). For film systems based on Co and $\mathrm{Cu}$ the form of hysteresis loop is the same as like for $\mathrm{Co}$ film. And during annealing to temperatures below $800 \mathrm{~K}$ is not changed. That confirming formation s.s. in condensation time and saving it in the specified temperature range. A partial decomposition of s.s. $(\mathrm{Cu}, \mathrm{Co})$ observed after annealing system to $1000 \mathrm{~K}$.

In the study of magnetoresistive properties can also be traced back some anisotropy magnetoresistance samples. The AMR is observed change-over from one geometry to another measurement. The AMR is observed when resistance of ferromagnetic material depends on the relative orientation of the magnetization vectors and the electric current density. Analysis of data for AMR indicates a general pattern of increasing the values of AMR for reducing the total concentration of atoms of magnetic components in three-layered systems.

Analysis MR data for $\mathrm{Co} / \mathrm{Ag} / \mathrm{Co} / \mathrm{S}$ system is indicated that increases the value $\mathrm{MR}$ in all three geometric at heat treatment up to $800 \mathrm{~K}$ and decreases after annealing to $900 \mathrm{~K}$. Results data from [14] is indicated about effect of the concentration atoms Co on MR in this system. It was found that the size dependence of MR for granular alloys formed after annealing $\mathrm{Co}(5) / \mathrm{Ag}(\mathrm{d}) \mathrm{Co}(5) / \mathrm{S}$ sandwich to $T_{a}=800$ and $900 \mathrm{~K}$. In three measurement geometries are nonlinear character. Maximum in the dependences is observed at the concentration of $\mathrm{Ag}$ atoms and $\mathrm{Co} 40$ and 60 at. \% respectively. The investigation $\mathrm{MR}$ for $\mathrm{Co} / \mathrm{Au} / \mathrm{Co} / \mathrm{S}$ are showing slight increase the value MR at $T_{a}=800 \mathrm{~K}$ and it decrease at $T_{a}=900 \mathrm{~K}$ in three geometric measurement.

In the work was investigated sandwiches based on Co and $\mathrm{Cu}$ with different concentration magnetic component $c_{C o}$. In this system isn't observed the AMR. The maximum value of $\mathrm{MR}$ in $\mathrm{Co}(14) / \mathrm{Cu}(\mathrm{d}) / \mathrm{Co}(14) / \mathrm{S}$ is in transversal geometry measurement. At the decreases thickness of intermediate $\mathrm{Cu}$ layer from 9 to $6 \mathrm{~nm}$ the magnetic field decreases from 200 to $100 \mathrm{mT}$ and increases sensitivity of the magnetic field from 1.2 to $2.8 \% / \mathrm{mT}$, respectively. The annealing samples, increasing the thickness of the nonmagnetic layer lead to an overall decrease of magnetoresistance. With increases concentration Co atoms in system increase and the value of MR. 

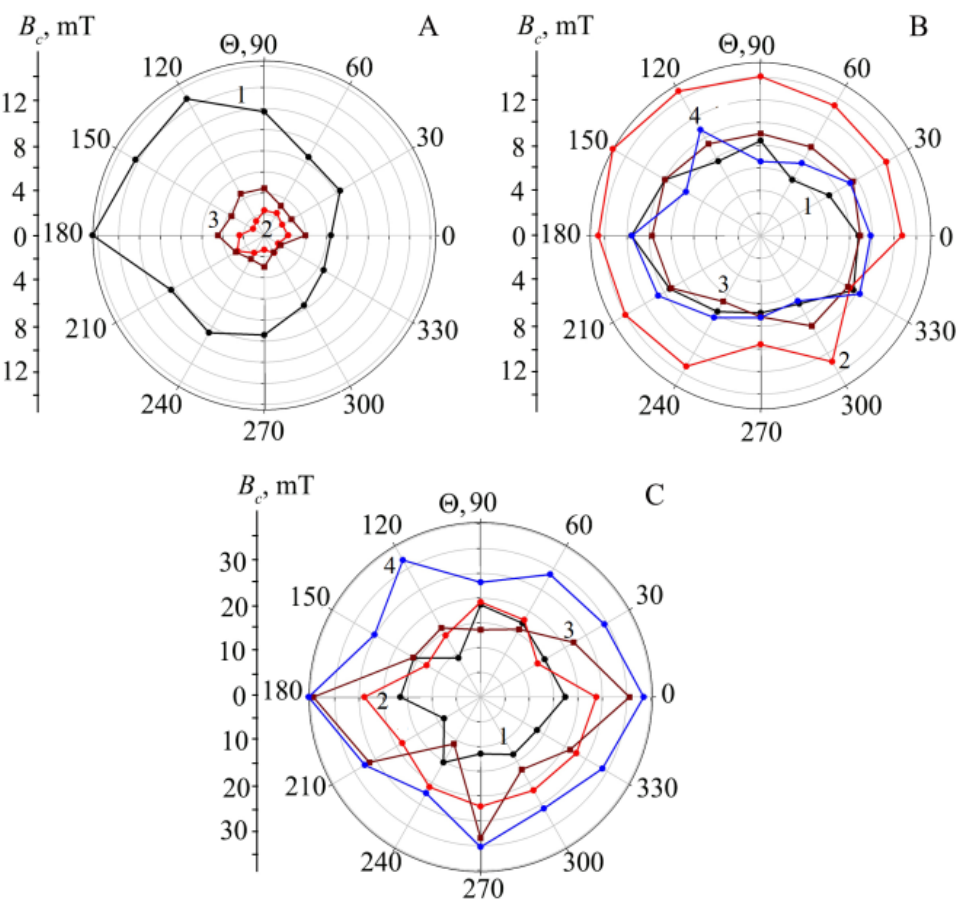

Figure 3. Coercivity $B_{c}$ dependence vs rotate angle for sandwich film system $\mathrm{Co} / \mathrm{Au} / \mathrm{Co} / \mathrm{S}$ in the plane of the film with different concentration $\mathrm{Co}$, at. \%: $\mathrm{A}-80 ; \mathrm{B}-88 ; \mathrm{C}-90$
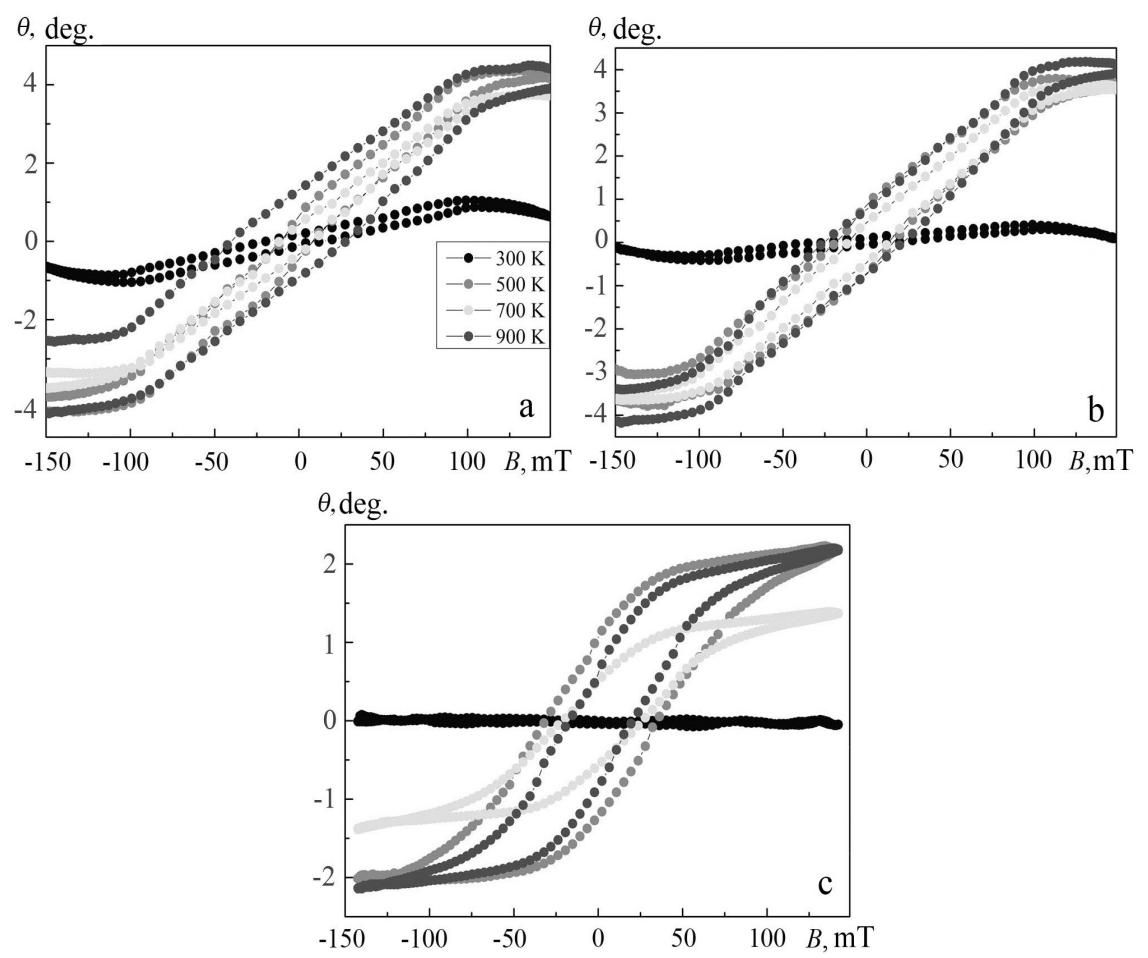

Figure 4. MOKE of $\mathrm{Co}(5) / \mathrm{Cu}(5) / \mathrm{Co}(5) / \mathrm{S}$ film system by the different annealing temperature out at three measurement geometries: longitudinal (A), longitudinal with changing the angle of rotation of the sample in the plane of the film (B) and perpendicular (C)

This is especially noticeable in the transverse geometry, in which at the concentration $c_{C o}=60$ and 87 at. \% the value MR is 0.2 and $0.4 \%$, and at the $c_{C o}=87$ at. \% - MR is 0.4 at. $\%$, respectively. Studied film systems are characterized by signs of GMR at values from 0.1 to $0.4 \%$ which a relatively large value of MR.

\subsection{MR of Film System Based on Fe and Ag}

In the film system based on $\mathrm{Fe}$ and $\mathrm{Ag}$ nucleation 
processes isn't observed. Simultaneous condensation metals and annealing to $800-1100 \mathrm{~K}$ in the system are realizing eutectic compound. The diffractions pattern is showing only bcc-Fe and fcc Ag. Fig. 5 is showing microstructure of thin films with total thickness $13 \mathrm{~nm}$ (Figure 5A) and $26 \mathrm{~nm}$ (Figure 5B) after annealing to $T_{a}=900 \mathrm{~K}$. In the figure can watch individual crystallites $\mathrm{Ag}$ and $\mathrm{Fe}$.

Magnetic properties this system depend on concentration magnetic component. In works $[16,17]$ and we have maximum MR value of samples with $c_{C o}=20-30$ at. $\%$ (Figure $6 \mathrm{~A})(\mathrm{d} \cong 20-30 \mathrm{~nm})$.
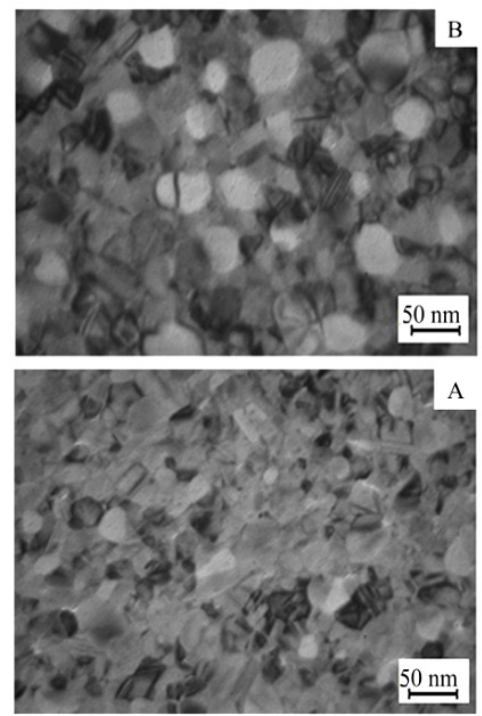

Figure 5. Microstructures of thin films $(\mathrm{Fe}+\mathrm{Ag}) / \mathrm{S}$ after annealing up to $900 \mathrm{~K}$. Thickness are 13 (A) and 26 (B) nm with total atom concentration of 30 at. $\% \mathrm{Fe}$

Change of the total thickness leads only to a change of value MR (Figure 6B), but does not influence on the shape of the general form dependence. Isotropic magnetic properties in research system based on $\mathrm{Fe}$ and $\mathrm{Ag}$ in throughout the range of concentrations and thickness is observed.

\section{Conclusions}

For the results of the studies found some patterns of the magnetoresistive and magnetooptical properties of the film systems based on $\mathrm{Co}, \mathrm{Cu}, \mathrm{Au}$ and $\mathrm{Ag}$, obtained layering condensation in which on the condensation stage or at a later annealing stage formed s.s. Can say that changes in dependencies MR and MOKE from total concentration of components in the system make it possible to trace the formation s.s. and, in some cases, its partial disintegration and transition systems to the granular state. So for the three-layer film systems based on $\mathrm{Co}$ and $\mathrm{Cu}$ common form of dependency MOKE and MR is different from addictions MOKE and MR from one-layer Co films, no significant changes after annealing because in this system the formation s.s. occurring at the condensation stage of component. In multilayer film systems in the annealing process, due to diffusion processes, was formation disordered s.s. and MOKE curves lose their characteristic rectangular shape. With further heat treatment in those systems is stabilisation the granular state of magnetic components in the nonmagnetic matrix s.s., as evidenced by some increase of the MR values at $T_{a}=800 \mathrm{~K}$. Unlike the $\mathrm{Co} / \mathrm{Cu} / \mathrm{Co}$ system in the system based on $\mathrm{Fe}$ and $\mathrm{Ag}$, even by the synchronous condensation of components and following annealing to $1100 \mathrm{~K}$ s.s. are not formed and magnetic properties of the system depend only on the concentration of magnetic components.
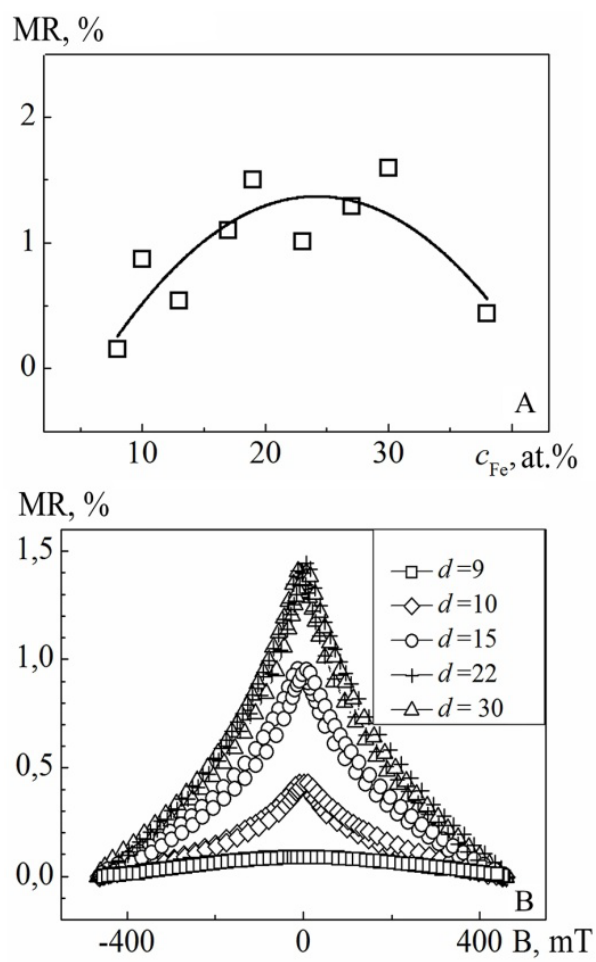

Figure 6. Concentration depending of $\mathrm{MR}$ of film systems $(\mathrm{Fe}+\mathrm{Ag}) / \mathrm{S}$ with total thickness $20 \mathrm{~nm}(\mathrm{~A})$ and film systems $(\mathrm{Fe}+\mathrm{Ag}) / \mathrm{S}$ with different thickness (B). $d=d_{\mathrm{Ag}}+d_{\mathrm{Fe}}(\mathrm{nm})$

\section{Acknowledgements}

We express our gratitude to Prof. I. Yu. Protsenko for the discussion of research results.

Work carried out with financial support from the Ministry of Education and Science of Ukraine (Grant № 0112U001381, 2012 - 2014).

\section{REFERENCES}

[1] F. Petroff, A. Barthelemy, D.H. Mosca, D.K. Lottis, A. Fert , P.A. Schroeder, W.P. Pratt, R. Loloee, S. Lequien. Oscillatory interlayer exchange and magnetoresistance in $\mathrm{Fe} / \mathrm{Cu}$ multilayers, Physical Review B, Vol.44, No10, 5355-5357, 1991.

[2] D.H. Mosca, A. Barthelemy, F. Petroff, A. Fert, P.A. 
Schroeder, W.P. Pratt. Oscillatory interlayer coupling and giant magnetoresistance in $\mathrm{Co} / \mathrm{Cu}$ multilayers, Journal of Magnetism and Magnetic Materials, Vol.94, No1-2, L1-L5, 1991.

[3] G.R. Pattanaik, S.C. Kashyap, D.K. Pandya. Structure and giant magnetoresistance in electrodeposited granular $\mathrm{Cu}-\mathrm{Co}$ films, Journal of Magnetism and Magnetic Materials, Vol.219, No2, 309-316, 2000.

[4] O.F. Bakkaloglu, I.H. Karahan. Magnetoresistance measurements on electrodeposited $\mathrm{CoCu}$ alloy films, Turkish Journal of Physics, Vol.25, No1, 27-35, 2001.

[5] H. Nabika, K. Akamatsu, M. Mizuhata, A. Kaiimani, S. Deki. Microstructure and electron transport properties of $\mathrm{Au}_{\mathrm{x}} \mathrm{Co}_{1-\mathrm{x}}$ nanoalloys embedded in polyacrylonitrile thin films, Journal Materials Chemistry, Vol.12, 2408-2411, 2002.

[6] S. Kenane, J. Voiron, N. Benbrahim, E. Chainet, F. Robaut. Magnetic properties and giant magnetoresistance in electrodeposited Co-Ag granular films, Journal of Magnetism and Magnetic Materials, Vol.297, No2, 99-106, 2006.

[7] I.V. Cheshko, I.Yu. Protsenko. The formation of metastability solid solution in film systems based on $\mathrm{Co}$ and $\mathrm{Cu}, \mathrm{Ag}$ or $\mathrm{Au}$, Metallophysics and Advanced Technology, Vol.31, No7, 963-967, 2009 (Rus.).

[8] N.P. Lyakishev. Diagrammy Sostoyaniya Dvoinykh Metallicheskikh System, Mashinostroenie, Moskva, 1996 (Rus.).

[9] M. Kitada. Magnitoresistance and microstructure of sputtered Au-Co films, Journal of Magnetism and Magnetic Materials, Vol.208, No3, 244-250, 2000.

[10] D.M. Kondrakhova, Yu.M. Shabelnyk, O.V. Synashenko, I.Yu. Protsenko. Structural and phase state, electrophysical and magnetoresistive properties of solid solutions in film systems based on $\mathrm{Co}$ and $\mathrm{Cu}, \mathrm{Ag}$ and $\mathrm{Fe}, \mathrm{Cr}$ or $\mathrm{Cu}$, Progress in Physics Metal, Vol.13, No3, 241-267, 2012 (Rus.).

[11] V.A. Zlenko, S.I. Protsenko, R. Safaric. Automated complex for thermoresistive properties investigation of nanostructured film systems, Journal of Nano- and Electronic Physics, Vol.1, No2, 34-41, 2009.

[12] G.I. Frolov, V.S. Gihalov, V.K. Mal'tsev. Vliyanie temperature na strukturnye prebrascheniya $\mathrm{V}$ nanokriatallicheskikh plenkakh kobal'ta, 2000, Physics of Solid State, Vol.42, No2, 326-328, 2000 (Rus.).

[13] M. Jergel, I. Cheshko, Y. Halahovets, P. Siffalovic, I. Mat' ko, R. Senderak, S. Protsenko, E. Majkova, S. Luby. Anneling behavior of structural and magnetic properties of evaporated Co thin films, Journal of Physics D: Applied Physics, Vol.42, No13, 135406-135414, 2009.

[14] W.E. Bailey, S.X. Wang, E.Yu. Tsymbal. Electronic scattering from $\mathrm{Co} / \mathrm{Cu}$ interfaces: In situ measurement and comparison with theory, Physical Review B, Vol.61, No2, 1330-1335, 2000.

[15] I.M. Pazukha, Yu.M. Shabelnyk, I.Yu. Protsenko. Magnetoresistive properties of granular films based on $\mathrm{Ag}$ and Co, Physics and Chemistry Solid State, Vol.13, No4, 907-915, 2012.

[16] J.-Q. Wang, G. Xiao. Transition-metal granular solids: Microstructure, magnetic properties, and giant magnetoresistance, Physical Review B, Vol.49, No6, 3982-3996, 1994.

[17] C. Alof, B. Stahl, M. Ghafari, H. Hahn. Interface contribution to giant magnetoresistance in granular $\mathrm{AgFe}$ studied with Mössbauer spectroscopy, Journal of Applied Physics, 2000, Vol.88, No7, 4212-4215, 2000 